\title{
A relational and processual perspective on good governance in sport
}

\section{Tackling the deeper problem}

\section{Maarten van Bottenburg}

\section{Introduction}

This chapter criticises the current approach to good governance in sport and the underlying rational actor theory for two shortcomings. (1) De-contextualisation: the focus is on the internal characteristics of organisations while ignoring the influence of the social context in general and inter-organisational power relations in particular. (2) De-historisation: attention is overly focused on the consequences that come with certain governance practices. This one-sided focus overlooks the social origins of those practices. As a result of these shortcomings, sport organisations remain subject to the same dynamics that cause government failures in the first place. As a consequence, these failures repeat themselves despite the codification of principles of good governance and the recurrent replacement of failing officials and key staff members.

To overcome these shortcomings, an additional theoretical perspective is needed; one that takes into account social and cultural conditions of governance practices and helps explain these practices stemming from inter-organisational power relations. Sociology offers various starting points for such a theoretical perspective, such as Diane Vaughan's situated action theory, Pierre Bourdieu's theory of practice and Norbert Elias' figuration theory. These scholars not only raise valid objections against the rational choice perspective in their work but also offer alternative theoretical notions that make it possible to better understand and explain why organisational misconduct and governance failures in sport organisations keep repeating, even as good governance codes are put into practice and failing executives are replaced. What these theories have in common is the integration of the micro (individual), meso (organisational) and macro (societal) levels of analysis. They also move beyond the dualism of structure and agency. Moreover, they analyse organisational practices as dynamic, on-going processes that are intertwined with a variety of other processes of change.

The chapter is structured as follows: First, it will illustrate the two points of criticism geared at the current approach to good governance. It connects these with a critical analysis of the underlying rational choice perspective. Then, based on the works of Vaughan, Bourdieu and Elias, and compatible governance and 
organisation theories, it lays out key components of a relational and processual approach that can broaden and enrich the theoretical perspective on good governance in sport. After that, it will discuss the implications of this additional theoretical lens for the analysis and approach of organisational misconduct and governance failures in the field of sport. Finally, it summarises the most important insights and reflect on the opportunities and limitations that the findings offer for further research as well as for application in practice.

\section{A critique of the good governance benchmark}

The first point of criticism concerns the focus on internal characteristics of sport organisations. Reform strategies, i.e. codes and indicators of good governance tend to address intra-organisational aspects of governance.

This can be illustrated with the Sports Governance Observer (SGO). The $\mathrm{SGO}$ is a benchmarking instrument that consists of a set of indicators of good governance. It has been developed to assess the governance of international sport federations. The aim is to employ this benchmarking instrument in order to provide an objective, reliable and holistic overview of which elements of good governance are implemented by these federations and which ones are not (Geeraert 2018).

In this benchmarking instrument, the notion of good governance is broken down into four sub-dimensions, namely transparency, democratic processes, internal accountability and control, and societal responsibility. 'Transparency' refers to the reporting of the organisation's own internal workings. 'Democratic processes' refer to having free, fair and competitive elections and open internal debates within the organisation. 'Internal accountability and control' refers to the separation of powers within the organisation's governance structure and to a system of rules and procedures that ensures staff and officials' compliance with internal rules and norms. Finally, 'societal responsibility' refers to deliberately directing the organisation to have a positive effect on internal and external stakeholders and society at large (Geeraert 2018).

These four dimensions are divided into 57 principles and 309 indicators, which require no further discussion. The four dimensions in themselves already show that the emphasis is clearly on the assessment of internal characteristics of individual organisations and independently of other organisations and the wider context. The fact that the SGO assumes an intra-organisational orientation is seen as an inevitable corollary of the underlying theory of the instrument (see also Chapter 12 by Geeraert on good governance indicators in this volume). This is, however, problematic considering that some of the issues which good governance in sport must tackle - the fight against corruption, doping, match fixing, human trafficking and money laundering-must be viewed in conjunction with the complex transnational sport governance system in which they operate as well as the social context in which organisational practices are formed. 
The second point of criticism concerns the focus on the consequences of governing failures ignoring underlying field dynamics. In other words, the current focus on (good) organisational governance fails to address the roots of many governance failures in sport, namely the social context in which individual and organisational behaviour and practices are formed, inter-organisational governance of global sport and the power relations that are characteristic for this governance structure. Examples related to FIFA and the World Anti-Doping Agency (WADA) can illustrate why this is problematic.

Of all the 35 Olympic international federations that were the subject of a study in the 2018 SGO, FIFA achieved the highest SGO 2018 index score as well as the highest scores associated with transparency, internal accountability and control, and societal responsibility. This achievement reflects the governance reforms FIFA had undertaken after 2011 (Geeraert 2018). Nevertheless, corruption and controversy have been ubiquitous ever since, particularly so in football. To illustrate, a report from the European Commission in July 2019 concluded that: "Professional football's complex organisation and lack of transparency have created fertile ground for the use of illegal resources. Questionable sums of money with no apparent or explicable financial return or gain are being invested in the sport. (...) Member States should consider which actors should be covered by the obligation to report suspicious transactions and what requirements should apply to the control and registration of the origin of the account holders and the beneficiaries of money" (European Commission 2019, p. 5, 18).

Apparently, the improvement of good governance in the international umbrella federation, in this case FIFA, has not prevented the problem of money laundering from taking on ever greater proportions. A check on compliance with the principles of good governance does not yet provide a grip on the underlying process that drives this problem. Theoretically, this should come as no surprise. Since the 1990s, scholars in political science, organisational science and public administration have convincingly argued that policy outcomes are not the product of actions by one single actor, but the consequence of the interaction of a network of interdependent actors. Their interaction patterns result in the institutionalisation of power relations and rules of behaviour that influence all actors involved (Klijn \& Koppenjan 2012). This also applies to the world of sport (Geeraert 2019; Henry 1999; Jedlicka 2018b).

The Russian doping scandal is a case in point. As one of the stumbling blocks in tackling this scandal, many have pointed to WADA's poor governance. The US government warned WADA that future funding from the United States could depend on the organisation's governance and enhanced transparency. The Institute of National Anti-Doping Organisations recommended the adoption of best governance practices, including organisational revisions leading to greater independence and transparency.

In a special issue of the International Journal of Sport Policy and Politics, several sport policy scholars reflect on this critique of WADA's poor governance. They 
sum up and analyse a variety of factors that challenge the effectiveness and legitimacy of WADA. However, they also conclude that "the fight against doping in sport is much stronger and more effective than in the 1990s" (Houlihan et al. 2019, p. 200), that "powerful interests have actively sought to undermine the effectiveness of WADA" (Houlihan et al. 2019, p. 194), and that there is an "apparent lack of regime effectiveness" which can partly be explained by "under-resourcing of anti-doping activity in some countries", "the lack of commitment by key stakeholders", and "the largely unsupportive environment" in which WADA has to "operate” (Houlihan \& Hanstad 2019, p. 203).

Here too, the question is whether an assessment of an organisation's compliance with good governance principles will get to the heart of the problem. In order to expose the underlying problem, WADA's governance failure must be related to developments in the broader organisational environment and to the changing power relations between organisations in that environment.

\section{A critique of the theoretical model underlying good governance}

Interestingly, these two criticisms of the good governance model are closely related to criticisms of the theoretical perspective that underlies this model. As Arnout Geeraert explains in Chapter 2 of this book, the principles enshrined in codes and indicators of good governance in sport organisations are often (implicitly) inspired by rational choice assumptions. His chapter clearly explains what the core assumptions of the rational choice approach are and how this approach translates into a regulatory system to promote good governance in sport organisations. Geeraert's argumentation needs no further clarification, but related to the present criticism, this author would like to highlight two key points.

First, rational choice theory is based on methodological individualism. It treats individuals, rather than social groups or societies as the basic units of analysis and tries to explain collective behaviour as the aggregation of choices by individuals. Collectives, i.e. organisations can be considered individual actors in rational choice theory just as much as actual individuals can be. An organisation can thus be the basic unit of analysis in relation to good governance. According to rational actor theory, the governance of sport as a whole can be improved if principles of good governance influence the behaviour of an individual organisation. It is therefore understandable that the focus is on intra-organisational characteristics in order to influence governance practices in the field of sport as a whole. Doing so, it should tackle wider problems that sport organisations face. However, this focus separates governance failures in sport organisations from their broader social and inter-organisational context.

Second, rational actor theory views individuals and organisations as conforming to bounded rationality and self-interest. Governance failures will persist unless the expected costs of undesirable behaviour exceed the expected benefits. 
To avoid misconduct, therefore, rules must be established to constrain and incentivise the execution of authority. They do so by influencing the distribution of information and altering the benefits and costs of an action. It is being assumed that negative sanctions should deter and thus prevent individuals and organisations from acting in an undesirable manner. This theoretical lens portrays executives and their organisations as 'amoral calculators' whose misbehaviour is motivated by a purely rational calculation of costs and opportunities. It pinpoints the cause of governance failure in an actor's rational calculations of the consequence of behaviour while ignoring its genesis. As such, it not only disregards the social context of governance practices but also overlooks their social origins.

\section{A processual and relational approach as alternative model}

Rational choice theory assumes that all human behaviour is ultimately interest-driven action. Sociology tells us, importantly, that this is too one-sided an emphasis on one mere dimension of meaningful action. Max Weber (1978) distinguished between goal-oriented rational action (calculation), value-oriented rational action (principle), traditional action (convention) and action from emotional or affective motivations (impulse). Following Weber, we can assume that people will often be guided in their behaviour by a varying mixture of these four types of social action.

This behaviour does not come about in a social vacuum. The institutional and organisational environment in which people are embedded influences cognition, narrows options and shapes preferences, as Diane Vaughan showed in her famous research on the fatal decision in 1986 to launch the Challenger Space Shuttle (Vaughan 1996). Research on organisational decision-making supports her finding. "The weighing of costs and benefits does occur, but individual choice is constrained by institutional and organisational forces" (Vaughan 1998, p. 29). Decision-making is not only based on cost-benefit calculation but also influenced by external contingencies, political battles, unacknowledged cultural beliefs, organisational routines and intuition based on past experience. Moreover, as James March and Johan Olsen argued in their 'garbage can model': decision-making in complex situations can be so dynamic and unpredictable that the outcome is driven more by accident, timing and choice opportunity than it is by careful analysis and deliberate choices (March \& Olsen 1979).

Based on her study, Vaughan (1998) proposes an alternative model that starts with contextualising decision-making and articulating social life as situated action. Social life produces tacit knowledge, habits, assumptions, routines and practices from which calculation and action emerge. This is in line with sociological institutionalism, which argues that decision-making may be rational, yet is affected by institutionalised categories of structure, thought and action, which shape preferences and direct choice towards some options rather than others. 
Pierre Bourdieu's theory of practice can be of help to further develop this model (Bourdieu 1977). He argues that social action cannot be reduced to rational choices because the conditions for rational calculation are often lacking: time is limited, information scarce, the alternatives are poorly defined and practical matters often require quick decisions. Instead of the product of rational calculation, Bourdieu postulates social action as resulting from a sens pratique, a "socially constituted 'sense of the game"' (Wacquant 1989, p. 42). This practical sense helps people to quickly understand the enormous multiplicity and complexity of possible goals, means and consequences. Based on previous experiences in similar situations, this enables them to make intuitive choices, such as the tennis player who suddenly 'decides' to enter the net or the football player 'deciding' to chip the ball over the goalkeeper (Bourdieu 1988).

To take a next step in developing an alternative model, we must widen the context of governance practices in organisations. Each organisation is embedded in a broader, inter-organisational and even transnational governance structure characterised by interdependencies and power balances, which influences organisations and individuals that operate within this structure. Norbert Elias' figurational sociology offers basic theoretical notions to elaborate on this. Elias uses the term figuration to express that human beings are fundamentally dependent on each other. They form interdependent relationships with unequal and variable power balances. Elias postulates that the behaviour of individual people and the problems of social life can only be understood properly by way of analysis of the asymmetrical interdependencies in the figurations that they form with each other, and thus, only by studying people in the plural and not in the singular (Elias 1978).

The same applies to organisations. Organisations are figurations of people, and at the same time, they form part of wider figurations of organisations (Elias 1983). "Just as human individuals only exist in relations of interdependence and power within organisations, the same is true of organisations themselves, which are also constitutively bound up in relations of interdependence and power with other organisations and figurations" (Van Krieken 2019, p. 163). This implies that good governance should not be investigated for organisations in the singular, but in the plural. Each sport organisation should be considered in conjunction with the transnational figuration of interdependent sport organisations and their stakeholders, in particular governments and business organisations, with their formative asymmetrical power balances. This figurational perspective differs fundamentally from rational choice theory, which does not explain organisational behaviour in relation to the wider figuration, but the wider figuration as the sum of the behaviour of individual organisations. From a figurational perspective, it follows that good governance issues cannot be properly understood if they are reduced to the sum of internal elements of organisations. They must be understood by studying these issues in their development (and thus by placing them in a historical context) and in conjunction with wider inter-organisational and societal developments. 


\section{Theoretical implications for good governance}

A relational and processual theoretical perspective contends that the interdependencies and power relations between governmental, commercial and sport organisations within transnational sport governance are co-determining. As such, they form a condition for compliance to good governance principles within organisations (see Figure 3.1).

In an analytical sense, this means that good governance should not only be seen as the independent variable; as cure for corruption and other issues in sport. It should also be regarded as a dependent variable: namely the product of a particular transnational institutional arrangement that has produced institutionalised codes and mores about 'how it works' in sport politics and sport governance; a product that also has an impact on organisational and individual behaviour and practices (cf. Jedlicka 2018a, 2018b).

In a normative sense, this means that additional principles should be developed for the impact of inter-organisational interdependencies on organisations and individuals. Concrete proposals for this have already been made in relation to network governance (Geeraert 2014; Geeraert, Scheerder \& Bruyninckx 2013; see also Chapter 13 by Kihl in this volume).

For example, in the current model of good governance in sport, corruption is a problem because it deviates from the way organisations should behave and thereby undermines the integrity of sport. It should, however, also be approached as a result of weakening errors in the governance of the world of sport as a whole.

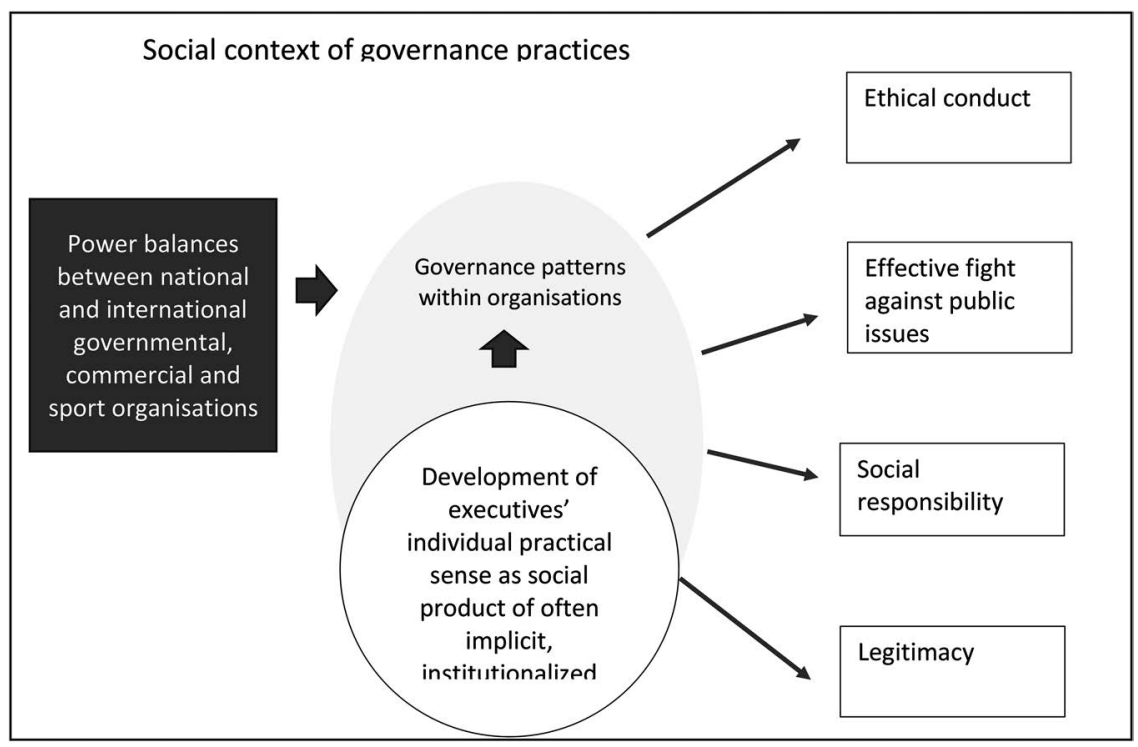

Figure 3.I A theoretical model of a relational and processual approach to good governance 
Sport organisations are not just a set of isolated, loosely bound organisations (Jedlicka 2018a, 2018b). They form a transnational figuration of organisations and are interdependent of each other and other stakeholders with varying power differences.

Following Ian Henry and Ping-Chao Lee (2004), this theoretical implication of a relational and processual perspective can also be expressed in a different way. The present theory and practice of good governance is too limited to pass as what they label as 'organisational governance'. This term is primarily concerned with normative, ethically informed standards of managerial behaviour within organisations. An important step forward from organisational governance would be to relate good governance to governance as networks (systemic governance) and governance as steering (political governance). Governance as networks is concerned with the competition, cooperation and mutual adjustment between organisations in the complex environment in which an organisation operates. Governance as steering relates to the processes by which governments or governing bodies seek to steer the sport system to achieve desired outcomes.

Henry and Lee (2004) define good governance as a normative approach, which requires sport organisations to conform to wider societal expectations of good practice. It also has implications for managers of such organisations. It can, however, be argued that this holds for systemic and political governance as well. As such, it would urge the need for cooperation between sport organisations and their stakeholders to tackle power positions and dependency relationships that provide incentives for governance failures and organisational misconduct.

The development of additional principles of good governance can be achieved by linking these governance approaches with a relational and processual sociological approach that connects behaviour at the network (macro) and organisational (meso) level to behaviour at the individual (micro) level. This will require more than just the application of governance network theory. It should not only put the behaviour of organisational actors in the context of inter-organisational power relations. It should also articulate decision-making as situated action; and thus pay attention to the often implicit institutionalised 'rules of the game' that direct individual behaviour within sport organisations.

A relational and processual perspective on good governance also sheds light on the knowledge gaps that Geeraert addresses in his introduction to this book. First, this perspective makes it understandable that working with a static intraorganisational focus leaves room for cosmetic reforms without substantial change. Adjustment of purely intra-organisational characteristics is insufficient to tackle the deeper problems of organisational misconduct and governance failures. This requires adhering to codes and changing attitudes, standards and mores. Such an ambition would require an additional approach aiming to alter the 'sense of the game'.

Second, a relational and processual perspective makes it understandable why good governance codifications proliferate. This can be seen as a typical example of isomorphism (DiMaggio \& Powell 1983). Organisations adopt characteristics 
of an organisational model that is seen or defined as desirable. They might do so without a clear diagnosis of the problem and without substantiated knowledge about the effects of means and methods they employ to tackle the problem. Nonetheless, they still invest time and energy in adhering to good governance principles, as they feel forced to do so or try to enhance their status and legitimation. This may strengthen their position in the field, but will not affect the underlying problem.

\section{Practical implications for good governance}

When looking through a relational and processual theoretical lens, it becomes clear that codification of good governance principles coupled with punitive, deterrent strategies will not suffice to improve the world of sport.

First, good governance policy should go beyond code compliance. In essence, it is about the question to what extent individual and organisational behaviour and practices do change, and where this change results from. To build on Weber's typology: Which routines are ingrained in organisations and to what extent are they changing? Which values are adhered to in the organisation, and to what extent do they change? What goals are pursued and what means are considered justified for this purpose? On which tacit knowledge and practical sense of 'how it works' in sport politics and sport governance are behaviour and decision-making based? Which 'rules of the game' do organisations adhere to?

Second, punitive, deterrent strategies will not suffice to improve the world of sport. Vaughan (1998) points to the fact that the rational choice model focuses on the responsible individuals and organisations to solve governance problems. This is done, for example, through ethics training, punishment, forced resignation and so forth. Such strategies are appropriate: people must be held responsible and accountable for action resulting in social harm. But these strategies are incomplete: they leave the social context untouched. As a result, the problem will not be solved once the responsible person is punished, and organisational misconduct and governance failures will be reproduced. "If the social context of decision making is not altered, the next position incumbent's decision making will be subject to the same organisational contingencies" (Vaughan 1998, p. 50).

Third, a punitive strategy should be augmented with an approach that works towards institutional reform (Vaughan 1998). Such an approach will only be successful if it is not only targeted at intra-organisational characteristics but also at inter-organisational interdependencies and thus the governance network in the field of sport as a whole. This calls for attention to the question of how organisations deal with their dependencies on other (public and private) organisations and what that means for all dimensions of good governance within their organisation.

Fourth, a relational and processual perspective requires an extension of the organisational governance model with a political and systemic governance focus. In this respect, the question is which principles the transnational sport governance figuration must adhere to in order to stimulate good governance within the 
organisations that are part of this figuration. It must also be worked out how, by whom and to whom reporting will take place on the dynamics and impacts of intra-organisational relationships in this figuration, as well as how organisations are accountable for this to their own stakeholders.

\section{Conclusion}

The current approach to good governance in sport falls short for two reasons. It overlooks both the social context and the social origins of governance practices within and by sport organisations. A relational and processual sociological perspective is needed to overcome these limitations. This perspective can help to contextualise organisational misconduct and governance failures at the micro, meso and macro levels.

At the micro level, a relational and processual perspective directs the attention to the practical sense of the rules of the game in the world of sport. Individual actors will develop this sense on the basis of previous experiences in comparable positions and circumstances. At the meso level, this perspective situates organisational action in social life, indicating that the individual actor is influenced by institutionalised beliefs, routines and social norms. At the macro level, this perspective points to the fact that organisational misconduct and governance failures cannot be solved by focusing solely on improving good governance within organisations. The focus should also be directed to the interdependencies within the transnational sport governance system and between sport organisations, governments and business organisations. Good systemic governance and good political governance are co-determining good organisational governance.

The implication of this perspective at the micro level is that an approach to good governance should go beyond code compliance. The deeper question is how individual and organisational behaviour and practices are formed and whether they change. This will require to 'unpack' often implicit, institutionalised codes about the 'rules of the game' that 'simply' apply in politics and 'cannot be ignored'. At the meso level, a punitive, deterrent strategy should be augmented with an approach that works towards changing the social and institutional context of decision-making. If this is neglected, individual actors will remain subject to the same dynamics. This is crucial to tackle sport's biggest problem with respect to today's good governance: organisational misconduct and governance failures keep repeating, even where good governance codes have been put into practice and failing executives have been replaced. Finally, at the macro level, additional principles should be developed for relationships between sport organisations and between sport organisations, government organisations and commercial organisations. Organisational misconduct and governance failures in sport cannot be solved by focusing solely on improving good governance within organisations.

The challenges posed by these implications are not easy to deal with. More attention should be paid to changing personal attitudes, moral standards, organisational mores and institutionalised codes underlying decision-making in sport 
organisations. However, those topics are difficult to grasp. In addition, the development of new good governance principles for political and systemic governance is still in its infancy. We can take this a step further by connecting relational and processual sociological theories to governance network theories.

\section{References}

Bourdieu, P 1977, Outline of a Theory of Practice, Cambridge University Press, Cambridge. doi:10.1017/CBO9780511812507

Bourdieu, P 1988, 'Vive la Crise! For Heterodoxy in Social Science', Theory and Society, vol. 17, no. 5, pp. 773-87. doi:10.1007/BF00162619

DiMaggio, PJ \& Powell, WW 1983, 'The Iron Cage Revisited: Institutional Isomorphism and Collective Rationality in Organisational Fields', American Sociological Review, vol. 48, no. 2, pp. 147-60.

Elias, N 1978, What is Sociology?, Columbia University Press, New York.

Elias, N 1983, The Court Society, Basil Blackwell, Oxford.

European Commission 2019, Report from the Commission to the European Parliament and the Council on the Assessment of the Risk of Money Laundering and Terrorist Financing Affecting the Internal Market and Relating to Cross-Border Activities, European Commission, Brussels.

Geeraert, A 2014, 'New EU Governance Modes in Professional Sport: Enhancing Throughput Legitimacy', Journal of Contemporary European Research, vol. 10, no. 3, pp. 302-21.

Geeraert, A 2018, Sports Governance Observer 2018. An Assessment of Good Governance in Five International Sports Federations, Play the Game/KU Leuven, Leuven.

Geeraert, A 2019, 'The Limits and Opportunities of Self-Regulation: Achieving International Sport Federations' Compliance with Good Governance Standards', European Sport Management Quarterly, vol. 19, no. 4, pp. 520-38. doi:10.1080/ 16184742.2018.1549577

Geeraert, A, Scheerder, J \& Bruyninckx, H 2013, 'The Governance Network of European Football: Introducing New Governance Approaches to Steer Football at the EU Level', International Journal of Sport Policy and Politics, vol. 5, no. 1, pp. 113-32. doi:10.1080/1 9406940.2012.659750

Henry, I 1999, 'Globalization and the Governance of Leisure: The Roles of the NationState, the European Union and the City in Leisure Policy in Britain', Society and Leisure, vol. 22, no. 2, pp. 355-79. doi:10.1080/07053436.1999.10715593

Henry, I \& Lee, P 2004, 'Governance and Ethics in Sport', in S Chadwick \& J Beech (eds), The Business of Sport Management.

Houlihan, B \& Hanstad, DV 2019, 'The Effectiveness of the World Anti-Doping Agency: Developing a Framework for Analysis', International Journal of Sport Policy and Politics, vol. 11, no. 2, pp. 203-17. doi:10.1080/19406940.2018.1534257

Houlihan, B, Hanstad, DV, Loland, S \& Waddington, I (eds) 2019, 'The World AntiDoping Agency at 20: Progress and Challenges', International Journal of Sport Policy and Politics, vol. 11, no. 2, pp. 193-201. doi:10.1080/19406940.2019.1617765

Jedlicka, SR 2018a, 'Appropriated Authority: A Theory of Transnational Sport Governance', International Journal of Sport Policy and Politics, vol. 10, p. 4, pp. 637-52. doi:10.1080/19406940.2018.1490334 
Jedlicka, SR 2018b, 'Sport Governance as Global Governance: Theoretical Perspectives on Sport in the International System', International Journal of Sport Policy and Politics, vol. 10, no. 2, pp. 287-304. doi:10.1080/19406940.2017.1406974

Klijn, EH \& Koppenjan, J 2012, 'Governance Network Theory: Past, Present and Future', Policy $\mathcal{E}$ Politics, vol. 40, no. 4, pp. 587-606. doi:10.1332/030557312X655431

March, JG \& Olsen, JP 1979, Ambiguity and Choice in Organisations, Universitetsforlaget, Bergen.

Van Krieken, R 2019, 'Norbert Elias and Organisational Analysis: Towards Process Figurational Theory', in S Clegg \& M Pina e Cunha (eds), Management, Organisations and Contemporary Social Theory, Routledge, Oxon, pp. 158-84. doi: 10.4324/9780429279591-9

Vaughan, D 1996, The Challenger Launch Decision: Risky Technology, Culture, and Deviance at NASA, The University of Chicago Press, Chicago. doi:10.7208/ chicago/9780226346960.001.0001

Vaughan, D 1998, 'Rational Choice, Situated Action, and the Social Control of Organisations', Law ES Society Review, vol. 32, no. 1, pp. 23-61. doi:10.2307/827748

Wacquant, LJ, 1989. Towards a Reflexive Sociology: A Workshop with Pierre Bourdieu, Sociological Theory, American Sociological Association, Washington, DC pp.26-63. doi: $10.2307 / 202061$

Weber, M 1978, Economy and Society. An Outline of Interpretive Sociology, University of California Press, Berkeley. 